\title{
Ischemic duodenitis without involvement of the large abdominal arteries
}

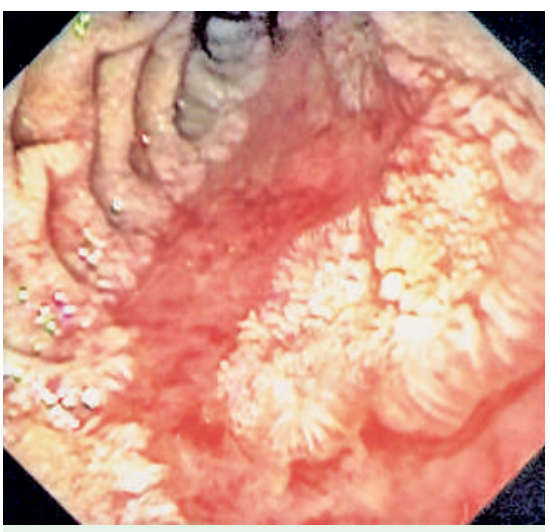

Fig. 1 A large longitudinal ischemic ulcer was seen in the descending part of the duodenum.

An 80-year-old woman presented with weight loss and diffuse abdominal pain that was worse after meals. She had a history of diabetes, hypertension, chronic renal insufficiency and chronic lymphatic leukemia. Palpation of the right lower abdominal quadrant was painful. Laboratory investigations, abdominal ultrasound, and a barium enema of the colon revealed no relevant abnormalities.

At gastroduodenoscopy an atypical area of inflammation was seen in the descending part of the duodenum ( Fig. 1). Histopathological examination showed nonspecific ulcerating inflammation ( Fig. 2). A presumptive diagnosis of ischemic duodenitis was made, but no stenoses of the large abdominal arteries were seen on duplex ultrasound examination. Omeprazole treatment was started and her symptoms diminished.

One year later she had a major cerebrovascular accident and died. An autopsy was performed. On gross examination, areas of ulceration were seen in the medial part of the duodenum, but there was no atherosclerosis in the major abdominal arteries. Remarkably, the smaller vessels of the duodenum and kidneys showed severe atherosclerosis. Microscopically, there was mucosal and submucosal ischemia with fibrosis in the abnormal parts of the duodenum.

Ischemic duodenitis has been associated with severe atheromatous disease of the

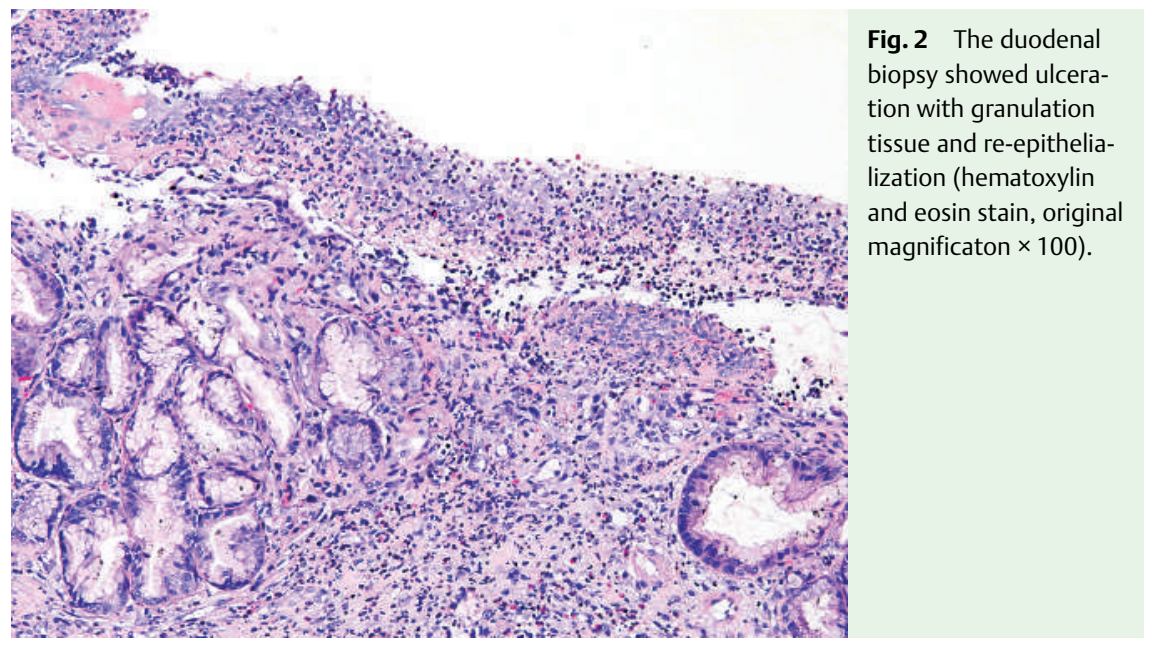

splanchnic arteries [1,2]. As far as we know, this is the first report of ischemic duodenitis caused by severe atherosclerosis of the duodenal arteries, but without involvement of the major abdominal arteries. Cholesterol emboli could not be excluded, but the absence of atherosclerosis in the major abdominal arteries makes this very unlikely [3]. There was no infiltration of lymphocytes, which suggests that there was probably no causative relationship with the chronic lymphatic leukemia either. Rare causes of ischemic gastrointestinal disease that can lead to similar endoscopic appearances, such as vasculitis or amyloidosis, were also ruled out on the basis of the radiological and histopathological findings [4]. A possible explanation in this case could be the gender differences in the pathophysiology of atherosclerosis: sometimes a more diffuse pattern of atherosclerosis can be seen in women, involving only the smaller arteries [5].

Endoscopy_UCTN_Code_CCL_1AB_2AZ_3AD

\section{Korswagen ${ }^{1}$, H. J. Voerman ${ }^{1}$, \\ J. L. Peterse ${ }^{2}$}

Department of Internal Medicine and Gastroenterology, Amstelland Hospital, Amstelveen, The Netherlands

2 Department of Pathology, The Netherlands Cancer Institute, Amsterdam, The Netherlands

\section{References}

1 Force T, MacDonald D, Eade $O E$ et al. Ischemic gastritis and duodenitis. Dig Dis Sci 1980; 25: $307-310$

2 Hojgaard L, Krag E. Chronic ischemic gastritis reversed after revascularization operation. Gastroenterology 1987; 92: 226-228

3 Kealy WF. Atheroembolism. J Clin Pathol 1978; 31: 984-989

4 Krupski WC, Selzman CH, Whitehill TA. Unusual causes of mesenteric ischemia. Surg Clin N Am 1997; 77: 471 - 502

5 Bugiardini R, Bairey Merz CN. Angina with "normal" coronary arteries: a changing philosophy. JAMA 2005; 293: 477-484

\section{Bibliography}

DOI $10.1055 / \mathrm{s}-2007-966610$

Endoscopy 2007; 39: E271

(c) Georg Thieme Verlag KG Stuttgart · New York . ISSN 0013-726X

\section{Corresponding author}

\section{Korswagen, MD}

Department of Internal Medicine and

Gastroenterology

Amstelland Hospital

PO Box 328

Amstelveen

$1180 \mathrm{AH}$

The Netherlands

Fax: +31-20-3474900

lindyanne_k@yahoo.com 